soon as possible at all levels, both institutionally and individually. The conference saw in the suggestionindicated here that academic disciplinary committees should be established for this purpose, one of the most hopeful signs for the future. It was considered that in their meetings in the future such academic disciplinary committees should consider the possibility of holding further confereicess of the kind held in Edinburgh.

\title{
MODERN TECHNIQUE IN RESTORATION OF ROMAN MOSAICS
}

$\mathrm{T}$ HERE is an inborn fascination to many of us, besides archaøologists and historians, in the discovery and unearthing of relics of life as it existed centuries ago. None of these is perhaps more generally exciting and popular than the Roman mosaic pavements, those skilfully constructed floorings in regular cubes of stone of many colours, beautifully contrived in patterns and pictures, frequently found in western Europe, far less common in Britain. Proof of life as it existed in Yorkshire during A.D. $100-400$, as evidenced by the discovery of two excellent examples of Roman mosaic handiwork, is furnished by the Rudstone pavement, a few miles inland from Bridlington (1933), and by one at Brantingham, near the north bank of the Humber, a few miles west of Hull, unearthed in 1962. Some faithfully illustrated records of these two mosaics and particularly the manner of their preservation are contained in a recent publication entitled Araldite in the Restoration of Roman Mosaics*.

At Rudstone three mosaics were originally uncovered and housed on site for many yoars. However, they began to deteriorate and were ultimately removed to Hull Museums for permanent preservation, this work being undertaken by the Museum staff and successfully completed in 1962. "One mosaie, $12 \frac{3}{4} \mathrm{ft} . \times 10 \frac{3}{4} \mathrm{ft}$., has a figure of Venus as its contrepiece; another, $11 \mathrm{ft}$. by $11 \mathrm{ft}$., shows a geometric pattern, while the third, depicting marine life, measures $10 \mathrm{ft}$. $\times 5 \mathrm{ft}$. These panels are now beautifully displayed in the museum." Their removal from site was, however, a matter of great concern and cost. The geometric panel, for instance, with its steel reinforcement, weighed $4 \frac{1}{2}$ tons; its display on a wall entailed the use of temporary scaffolding for its erection, a costly and laborious job. The lessons had been learnt with these Rudstone mosaics the hard way; when it came to the question of lifting the newly discovered Brantingham pavement, different methods of preservation were resorted to, involving the use of an 'Araldite' (CIBA) epoxy resin formulation and a novel technique.

The Brantingham pavement apparently formed the floor of the largest room in what is thought to have been a distinguished Romano-British villa. It originally measured $36 \mathrm{ft}$. $\times 26 \mathrm{ft}$. It is the largest example of Roman mosaic work so far discovered in Yorkshire. Unfortunately part of this mosaic had suffered damage by * Ciba (A.R.I.), Ltd., Technical Notes (July, 1965): Araldite in the
Restoration of Roman Mosaics. Pp. 12. (Duxford: Ciba (A.R.L.), Ltd., Restoratio
1965.) collapse into flues of an underlying hypocaust, but a number of large panels were well preserved, removed, and are now in course of preparation for exhibition in Hull Museums. Some smaller sections of the mosaic were taken away flat, but other larger portions were transported by what is known as the 'rolling-up' technique. Briefly, the procedure is as follows: to ensure absence of moisture, a metal scaffold frame is erected over the pavement and on this a plastic sheet is stretched; butane gas heaters are then directed on to the pavement for some three days or so; at the end of this drying, two coats of a polyvinyl. chloride solution are spread over the mosaic, a bandage material laid thereon, and a top sealing coat of polyvinyl. chlorido. The next operation-a difficult one-is the actual rolling up of the pavement; according to this account: "This was done on a cardboard roller, $2 \mathrm{ft}$. in diameter, strengthened internally and filled with a suitable axle. The tesserae (the individual stone cubes forming the pavemont) were cut away from the mortar with long iron blades and several workers helpod to turn the roller and ensure that the pavement was evenly wound. As they went on to the roller, the layers were interleavod with two sheets of corrugated paper and a strong dust sheet which was pulled tightly over the tesserae to keep them in place". "Thus the sections of the pavement are transported to the museum.

The unrolling stage is the next oporation and it is here? that the 'Araldite' resin plays its part. The major' sections of the pavement are unrolled face down on th sloping surfaco; the cdges are boxed in with timber to make a container for the backing; any loose mortar is cleaned off; then an 'Araldite' coat is applied together with chopped glass fibre. Finally, this is backed up with $2 \mathrm{in}$. of vermiculite and iron reinforcing bars bonded with an 'Araldite' resin formulation. The whole process results in a light but rigid structure. Compared with the Rudstone mosaic panels, it is estimated that this technique results in the weight of the Brantingham panels being less than a quarter per unit area.

The great advantages of these cured 'Araldite' epoxy resins for this sort of work are their stability, resistance to chemical attack and moisture. Furthormore, they possess strong adherent properties to a host of different materials, such as stone, glass fibre and vermiculite. It is indeed no boastful claim that ". . . these beautiful pavements are now permanently preserved for the benefit of posterity ..."

\section{A PROPOSAL ON NATURE'S TIME-SCALE}

\section{By PROF. NEIL G. MCCORMICK}

Department of Microbiology, School of Medicine, University of Virginia, Charlottesville

T has become increasingly obvious through the various
cosmological and relativity theories that we live in a
non-linear universe. As has been aptly pointed out ${ }^{1}$, there
is a tendency to make simplifying assumptions about all
observable phenomona in order to explain them in a linear
manner. In a way this has lulled us into the belief that
most processes may be considered to exist in some theoreti-
cally idealized state. Hence, many observations of non-
linear processes are compromised by considering ". . .
equations to be linear for a suffieiently small displacement
..." or, ". . in a certain range the curve can bo approxi. mated by straight lines as shown". However, these idealized assumptions (that is, homogeneity, frictionlessness, weightlessness, temperature of absolute zero, perfect gas, perfect vacuum, etc.) are nover observed in reality, and in all likelihood never occur in Nature. Fven though such assumptions may aid greatly in understanding the mechanisms involved, they do not lead to a complete description of the process. As stated by D. W. Thompson ${ }^{2}$ in a discussion concerning the regeneration of tadpole 